\title{
Development of a Performance Calculation Program for Solar Domestic Hot Water Systems with Improved Prediction of Thermal Stratification
}

\author{
Fan, Jianhua; Furbo, Simon; Li, Zhe
}

Published in:

Conference Proceedings - Solar World Congress 2015

Link to article, DOI:

10.18086/swc.2015.02.15

Publication date:

2016

Document Version

Publisher's PDF, also known as Version of record

Link back to DTU Orbit

Citation (APA):

Fan, J., Furbo, S., \& Li, Z. (2016). Development of a Performance Calculation Program for Solar Domestic Hot Water Systems with Improved Prediction of Thermal Stratification. In Conference Proceedings - Solar World Congress 2015 International Solar Energy Society. https://doi.org/10.18086/swc.2015.02.15

\section{General rights}

Copyright and moral rights for the publications made accessible in the public portal are retained by the authors and/or other copyright owners and it is a condition of accessing publications that users recognise and abide by the legal requirements associated with these rights.

- Users may download and print one copy of any publication from the public portal for the purpose of private study or research.

- You may not further distribute the material or use it for any profit-making activity or commercial gain

- You may freely distribute the URL identifying the publication in the public portal 


\title{
DEVELOPMENT OF A PERFORMANCE CALCULATION PROGRAM FOR SOLAR DOMESTIC HOT WATER SYSTEMS WITH IMPROVED PREDICTION OF THERMAL STRATIFICATION
}

\author{
Jianhua Fan', Simon Furbo' ${ }^{1}$ and Zhe $\mathrm{Li}^{2}$ \\ ${ }^{1}$ Department of Civil Engineering, Technical University of Denmark, Denmark \\ ${ }^{2}$ Beijing Computing Center, Beijing, China
}

\begin{abstract}
The transient fluid flow and heat transfer in a hot water tank during cooling caused by standby heat loss were investigated by computational fluid dynamics (CFD) calculations and by thermal measurements in previous investigation. It is elucidated how thermal stratification in the tank is influenced by the natural convection and how the heat loss from the tank sides will be distributed at different levels of the tank at different thermal conditions.

A heat loss removal factor is introduced to characterize the effect of the buoyancy driven flow on exchange of heat loss between tank layers by natural convection. Based on results of the CFD calculations, a generalized equation of the heat loss removal factor is obtained by regression which calculates the heat loss removal factor for a given temperature gradient in the tank. The equation takes into account the influences of tank volume, height to diameter ratio, tank insulation, thickness and material property of the tank wall and initial thermal conditions of the tank. The equation is validated for a tank volume in the range of 1501 and 5001 and a height to diameter ratio of 1-5. The equation is implemented in a simulation program for a solar domestic hot water (SDHW) system with a hot water tank charged by a built-in heat exchanger spiral. The program can calculate thermal performance of a SDHW system. Thermal performance calculated by the program will be compared to the measurements. The investigations elucidate accuracy and reliability of the program for calculation of temperatures and thermal performance of a solar domestic hot water system.
\end{abstract}

Keywords: Hot water tank, thermal stratification, performance calculation program, Computational fluid dynamics (CFD), Heat loss removal factor

\section{Introduction}

Thermal stratification in solar storage tanks has a major influence on the thermal performance of solar heating systems. A high degree of thermal stratification in the storage tank increases the thermal performance of a solar heating system because the return temperature to the solar collector is lowered (Furbo 1984, van Koppen C 1979, Furbo 1987, Haller 2009, Haller 2010). A lower inlet temperature to the solar collector will increase the efficiency and operating hours of the solar collector. Further, the temperature at the top of the storage will be closer to the desired load temperature. Therefore the auxiliary energy consumption will be decreased which increases the solar fraction (Hollands 1989, Furbo 2006).

Heat loss from the tank sides helps to build up thermal stratification in the tank. Due to heat loss to the surroundings, the fluid close to the tank wall has a lower temperature than the fluid at the centre of the tank. The relative colder fluid flows downwards along the tank wall while the fluid with higher temperature rises up in the centre of the tank.

Thermal stratification and natural convection flow in a vertical cylindrical hot water tank during standby periods were investigated in the literature (Andersen 2007, Fan 2012a). Transient, three-dimensional CFD models of hot water storage tanks were developed and validated against thermal measurements. Zachar carried out a numerical analysis of flow distributors to improve temperature stratification in storage tanks (Zachar 2007). Neural network modelling was used for calculation of thermal stratification in a solar DHW storage (Geczy-Vig 2010).

The aim of the investigation is to elucidate how thermal stratification in the tank is influenced by the natural 
convection and how the heat loss from the tank sides will be distributed at different levels of the tank at different thermal conditions. The ultimate goal of the investigation is to improve an existing program for performance calculation of solar domestic hot water systems in terms of prediction of thermal stratification in the tank.

\section{The experimental and numerical investigations}

Experimental investigations were carried out on a slim 1501 tank with a diameter of $0.34 \mathrm{~m}$ and a height of $1.68 \mathrm{~m}$ in order to evaluate the effect of heat loss on thermal stratification in a tank. The height to diameter ratio of the tank is 5.0. The tank is made of steel with a thickness of $5 \mathrm{~mm}$ and is insulated with $5 \mathrm{~cm}$ mineral wool. Temperature distribution of the tank is measured with 14 copper/constantan thermocouples (type TT) equally placed from the bottom to the top of the tank. The heat loss coefficient from different parts of the tank is measured with the setup shown in Fig. 1. During the measurements, the tank is heated by an electric heating element to a uniform constant temperature. The electric heating element is placed at the very bottom of the tank. The heat loss from the tank is therefore equal to the power consumption of the electric heating element under steady state conditions. Measurement of the heat loss coefficient from different parts of the tank is possible with help of the iso-temperature box which is kept at the same temperature as the water temperature in the tank. A uniform temperature of the air in the box is achieved as the air is fully mixed by means of a fan inside the box. Therefore there is no heat loss from the part of the tank covered by the box. Air temperature in the box and ambient air temperature are measured by copper/constantan thermocouples, type TT. By means of measurements with different positions of the box and with two temperature levels of $76.0^{\circ} \mathrm{C}$ and $36.5^{\circ} \mathrm{C}$, the distribution of the heat loss coefficient for the different parts of the tank is determined for different temperature levels. The measurement accuracy of temperatures is $0.5 \mathrm{~K}$. For the temperature level of $36.5^{\circ} \mathrm{C}$, the total heat loss coefficient of the tank is measured. The heat loss coefficients for the different parts of the tank are obtained by assuming the same distribution of the heat loss coefficients among the different tank parts as with a hot water temperature of $76{ }^{\circ} \mathrm{C}$. Since the distribution of the heat loss coefficient for different parts of the tank is mainly dependent on the tank design and insulation, the assumption will not introduce significant errors in the analysis. Linearly temperature dependent heat loss coefficients for different parts of the tank are then obtained, see Equation 1-4.

$\begin{array}{lll}K_{\text {top }}=0.24+0.00015 *(\mathrm{~T}-273.15) & {[\mathrm{W} / \mathrm{K}]} \\ K_{\text {side }}=1.75+0.00148 *(\mathrm{~T}-273.15) & {[\mathrm{W} / \mathrm{K}]} \\ K_{\text {bottom }}=0.41+0.00034^{*}(\mathrm{~T}-273.15) & {[\mathrm{W} / \mathrm{K}]} \\ K_{\text {total }}=2.4+0.00198 *(\mathrm{~T}-273.15) & {[\mathrm{W} / \mathrm{K}]}\end{array}$

where $\mathrm{T}$ is the water temperature in the tank, $[\mathrm{K}]$.

The measured heat loss coefficients of the tank are used as inputs to the numerical investigations.

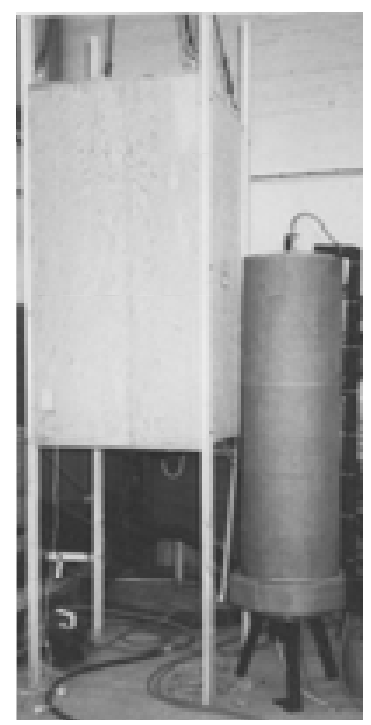

A. The Iso-temperature box and the tank

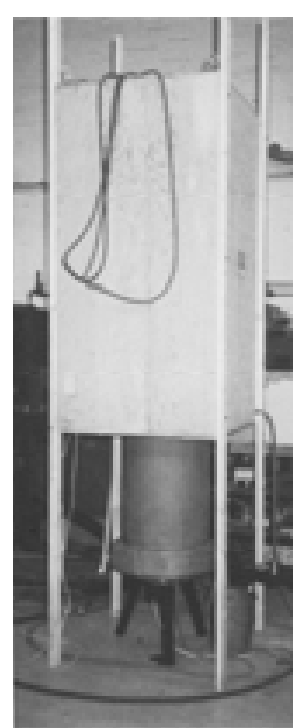

B. Measurement of tank heat loss coefficient

Figure 1. Experimental setup 
A tank simulation program (SpiralSol) has been developed to calculate water temperatures in a tank with a built-in heat exchanger spiral (Furbo 1984). Thermal stratification in the tank under different operating conditions is considered. The program is able to determine the thermal performance of a solar heating system taking into consideration thermal stratification in the tank. The program is improved in this paper in the term of prediction of thermal stratification by considering the influence of buoyancy driven flow along the tank side wall.

In the program, the tank is equally divided into a number of layers $(\mathrm{N}=10)$, numbered sequentially from the bottom to the top of the tank, see Fig. 2. Heat loss from the side of the layer I is defined as $\mathrm{Q}_{\text {loss }}(\mathrm{I})$ calculated based on conventional heat transfer theory while the heat loss moving from the layer above (I+1) to the layer (I) due to the buoyancy driven flow is defined as $\mathrm{Q}_{\text {flow }}(\mathrm{I})$. A heat loss removal factor $a(I)$ for interface $I$ is defined as the ratio between the heat loss moved down by natural convection and the total amount of heat loss of the layer. The heat loss of the layer includes both heat loss from the side of the tank and the heat loss moved down from the layer above.

$$
a(I)=\frac{Q_{\text {flow }}(I)}{Q_{\text {flow }}(I+1)+Q_{\text {loss }}(I+1)}
$$

For the top layer N, the heat loss moving from the layer above is replaced by the heat loss from the top of the tank.

$$
a(N-1)=\frac{Q_{\text {flow }}(N-1)}{Q_{\text {top loss }}+Q_{\text {loss }}(N)}
$$

Thermal stratification in the tank is characterized by a temperature gradient $\operatorname{Gr}(\mathrm{I})$.

$$
\operatorname{Gr}(I)=\frac{T_{\text {layer }}(I+1)-T_{\text {layer }}(I)}{H_{\text {layer }}(I+1)-H_{\text {layer }}(I)}
$$

where $\mathrm{T}_{\text {layer }}(\mathrm{I})$ is the average fluid temperature of layer $\mathrm{I}$ in $\mathrm{K}$, while $\mathrm{H}_{\text {layer }}(\mathrm{I})$ is the average height of layer I in $\mathrm{m}$ measured from the bottom of the tank.

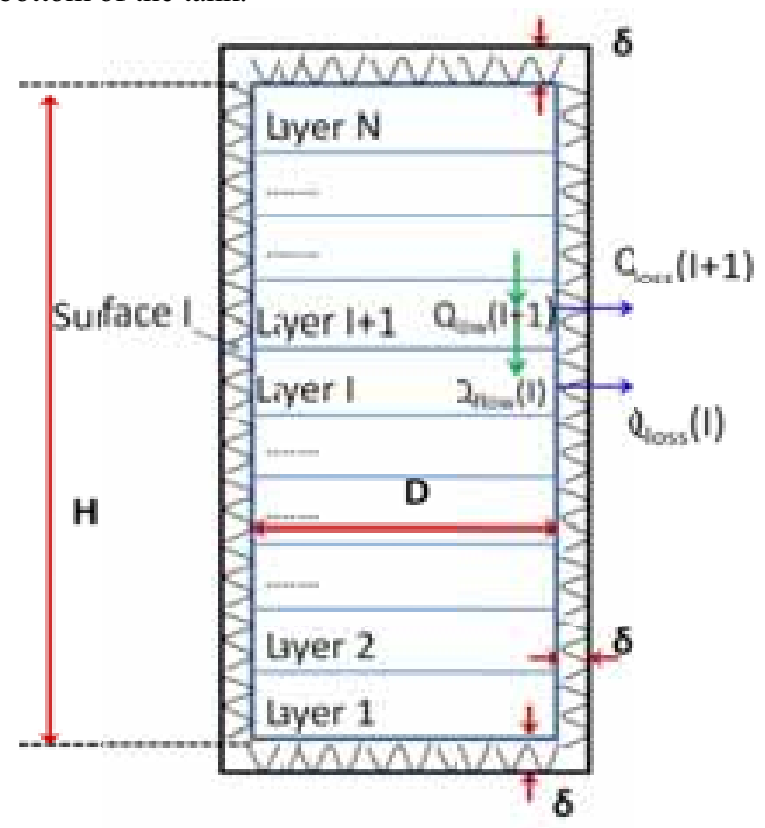

Fig. 2 Schematic illustration of a tank consisting of $\mathbf{N}$ layers.

\section{The downwards flow along tank wall due to heat loss from the tank}

\subsection{The initial conditions of the tank}


CFD model of the slim hot water tank has been developed and validated against measurements (Fan 2012a). Calculations have been made using the validated CFD models to investigate the influence of the downward flow along the tank wall due to heat loss from the tank. The initial condition of the tank was either a fully charged tank with a uniform water temperature of $80{ }^{\circ} \mathrm{C}$ or a stratified tank after a hot water draw-off. In the stratified tank, the water temperature at the upper part of the tank is $80{ }^{\circ} \mathrm{C}$ while it is $17{ }^{\circ} \mathrm{C}$ at the bottom of the tank. Fig. 3 shows the temperature profile of the stratified tank after a hot water draw-off. The stratified tank corresponds to a tank after a hot water draw-off of 75 liters.

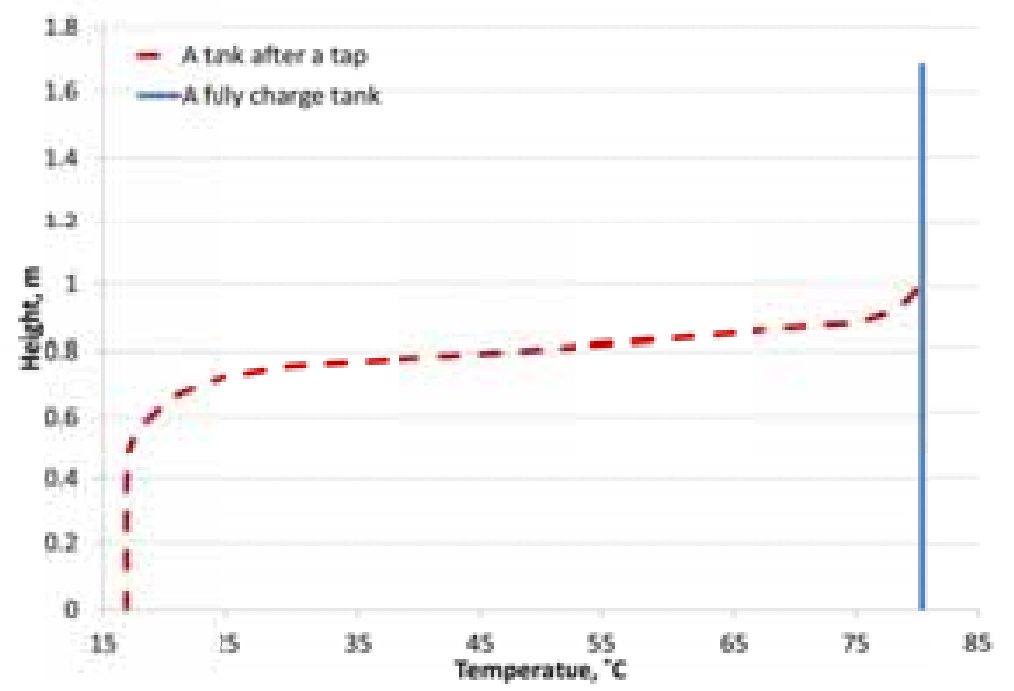

Fig. 3 Temperature profile of a fully charged tank and of a stratified tank after a hot water draw-off

3.2 The dependence of downward velocity on temperature gradient during standby period of a fully charged tank

Fig. 4A shows water temperatures in the tank after 24 hours standby of a fully charged tank. Due to heat loss from the tank, water temperature at the upper part of the tank drops by $14 \mathrm{~K}$, while att the bottom of the tank water temperatures decreases by $27 \mathrm{~K}$. In the tank with a height $0.24 \mathrm{~m}-1.68 \mathrm{~m}$ from the bottom of the tank, there is a temperature of $64-66^{\circ} \mathrm{C}$, indicating a small temperature gradient. In the lower $24 \mathrm{~cm}$ of the tank there is a larger temperature difference.
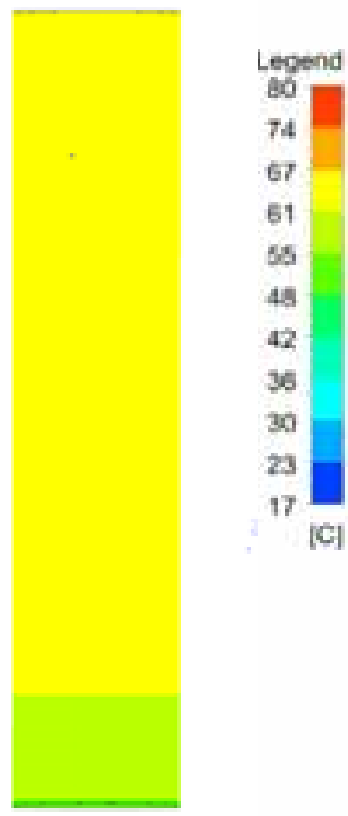

A. Temperature distribution

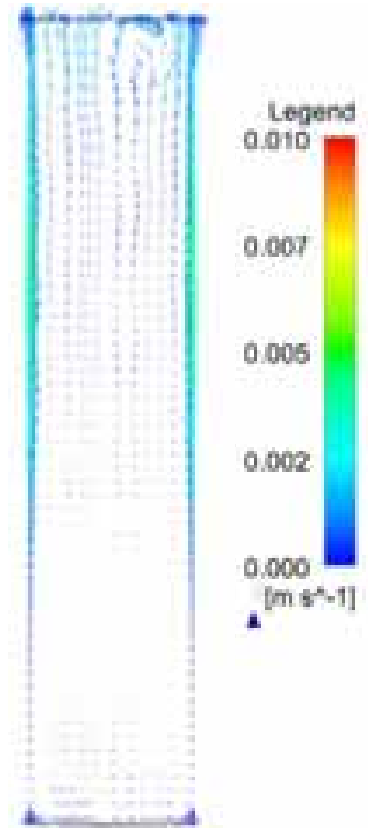

B. Velocity vectors

Fig. 4 CFD calculated velocity vectors and temperature distribution in the tank after a 24 hours standby period with an originally fully charged tank. 
Fig. 4B shows velocity vectors of fluid flow in the tank after a 24 hours standby period starting with a fully charged tank. Due to heat loss from the tank side, water close to the tank side has a lower temperature than water in the center of the tank at the same height. The colder water tends to flow downwards along the tank side wall as its density is higher, while in the center of the tank warmer fluid tends to flow upwards, creating a water circulation in the tank. The buoyancy induced flow will drive fluid with lower temperature from the upper part of the tank to the bottom part of the tank, consequently establishing thermal stratification during standby period of the tank. Temperature gradient in the tank has a significant influence on the downward flow along the tank side wall. Fig. 5 shows dependence of downward velocity on temperature gradient in the tank after 24 hours standby cooling of a fully charged tank. It is shown that the larger the temperature gradient, the lower the downward flow is. At height in the range of $0.7-1.68 \mathrm{~m}$ where the temperature gradient is as low as $0-2 \mathrm{~K} / \mathrm{m}$, the average downward flow velocity is $1 \mathrm{~mm} / \mathrm{s}-7 \mathrm{~mm} / \mathrm{s}$. While at the bottom of the tank (at height $0-0.6 \mathrm{~m}$ ) where there is a larger temperature gradient in the range of $3-25 \mathrm{~K} / \mathrm{m}$, the downward flow is significantly reduced to be lower than $1 \mathrm{~mm} / \mathrm{s}$.

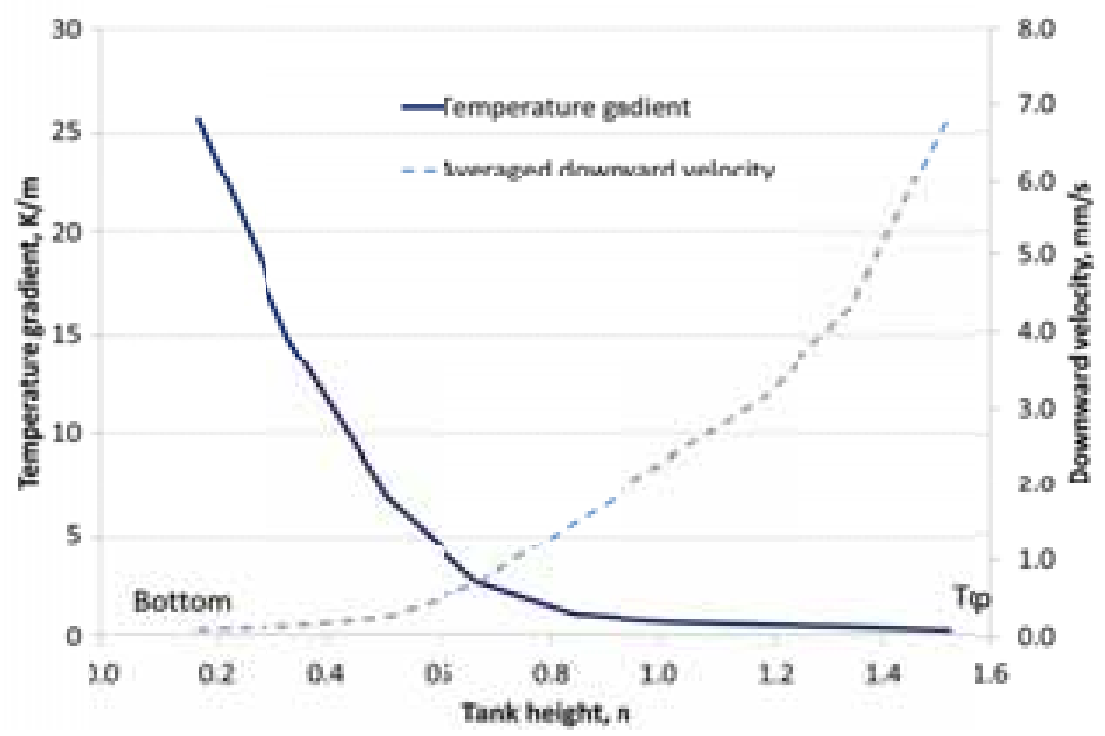

Fig. 5 Dependence of downward velocity on temperature gradient in the tank after a 24 hours standby period starting with a fully charged tank.

\subsection{The dependence of downward velocity on temperature gradient during standby period of a stratified tank}

The buoyancy driven flow in a stratified tank is investigated as well. Fig. 6A shows the temperature distribution in the tank at 5 hours standby of a stratified tank. At the upper part of the tank there is a water temperature of $70-75^{\circ} \mathrm{C}$ while the water temperature at the bottom of the tank is almost constant at $17^{\circ} \mathrm{C}$. Fig. 7 shows temperature gradient versus water temperatures in the tank. In the middle part of the tank there is a strong thermal stratification with a temperature increase of $47 \mathrm{~K}$ from $0.5 \mathrm{~m}$ to $1.2 \mathrm{~m}$ height of the tank, corresponding to a temperature gradient in the range from $44 \mathrm{~K} / \mathrm{m}$ to $99 \mathrm{~K} / \mathrm{m}$. At the top of the tank with a height in the range from 1.2 to $1.68 \mathrm{~m}$, the temperature gradient is smaller than $20 \mathrm{~K} / \mathrm{m}$. The temperature gradient is small as well at the bottom of the tank with a height from 0 to $0.4 \mathrm{~m}$.

From Fig. 6B it can be seen that there is a downward flow along the tank wall at the height of $1.4 \mathrm{~m}$ or higher due to the absence of stratification. Water in the central parts of the tank water is flowing upwards as water in the center of the tank is relatively warmer. At the height of $1.1 \mathrm{~m}$, the downward flow is reduced significantly, which can be explained by the presence of strong stratification at that part of the tank. At the bottom of the tank there is a small temperature gradient but the downward buoyancy driven flow is not present. However a small uprising flow along the tank wall can be observed. The rising flow has the magnitude of approx. $0.4 \mathrm{~mm} / \mathrm{s}$. This can be explained by a warmer steel tank wall at the bottom of the tank caused by heat gain from the upper part of the tank due to thermal conduction through the tank wall and from the ambient air which has a slightly higher temperature. The heat gain heats up the fluid adjacent to the wall, creating upward flow. 


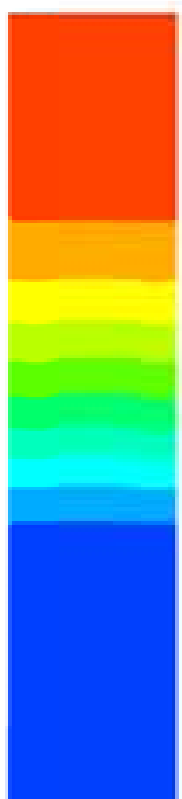

A. Temperature distribution

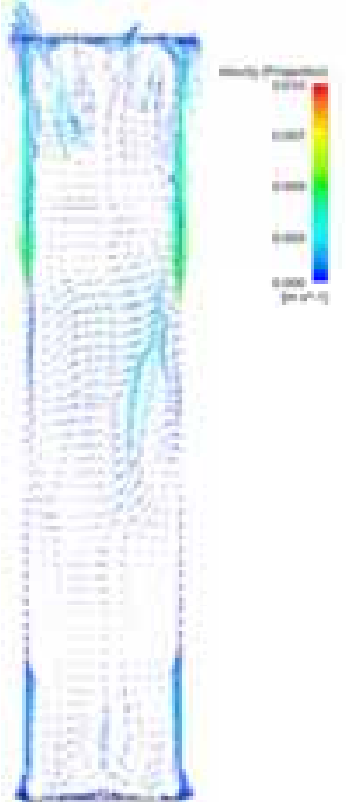

B. Velocity vectors

Fig. 6 CFD calculated velocity vectors and temperature distribution in the tank after 5 hours of standby with an originally stratified tank.

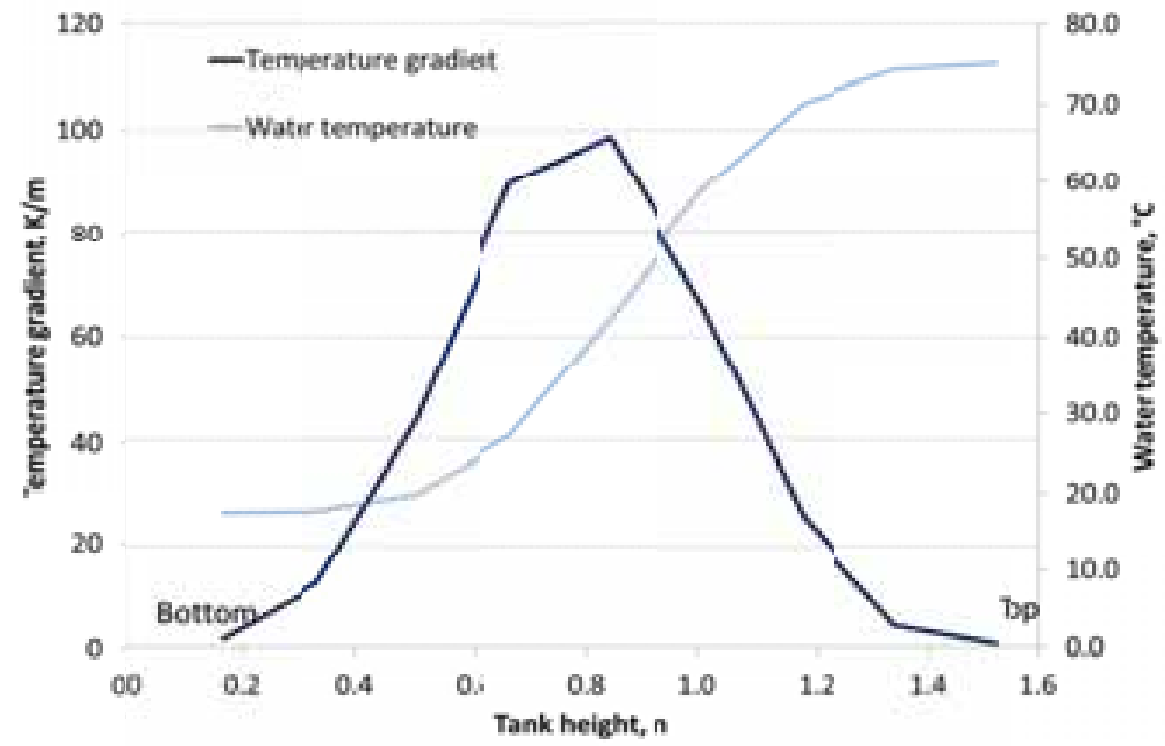

Fig. 7 Temperature gradient in the tank after 5 hours of standby for a stratified tank.

Fig. 8 shows the dependence of downward flow along the tank side wall on temperature gradient in the tank. At the top of the tank where there is a small temperature gradient, the downward flow has an average speed of $1 \mathrm{~mm} / \mathrm{s}-4.5 \mathrm{~mm} / \mathrm{s}$. While the flow is significantly reduced in the middle part of the tank with a height from $0.4 \mathrm{~m}$ to $1.2 \mathrm{~m}$ where there is a temperature gradient higher than $20 \mathrm{~K} / \mathrm{m}$. 


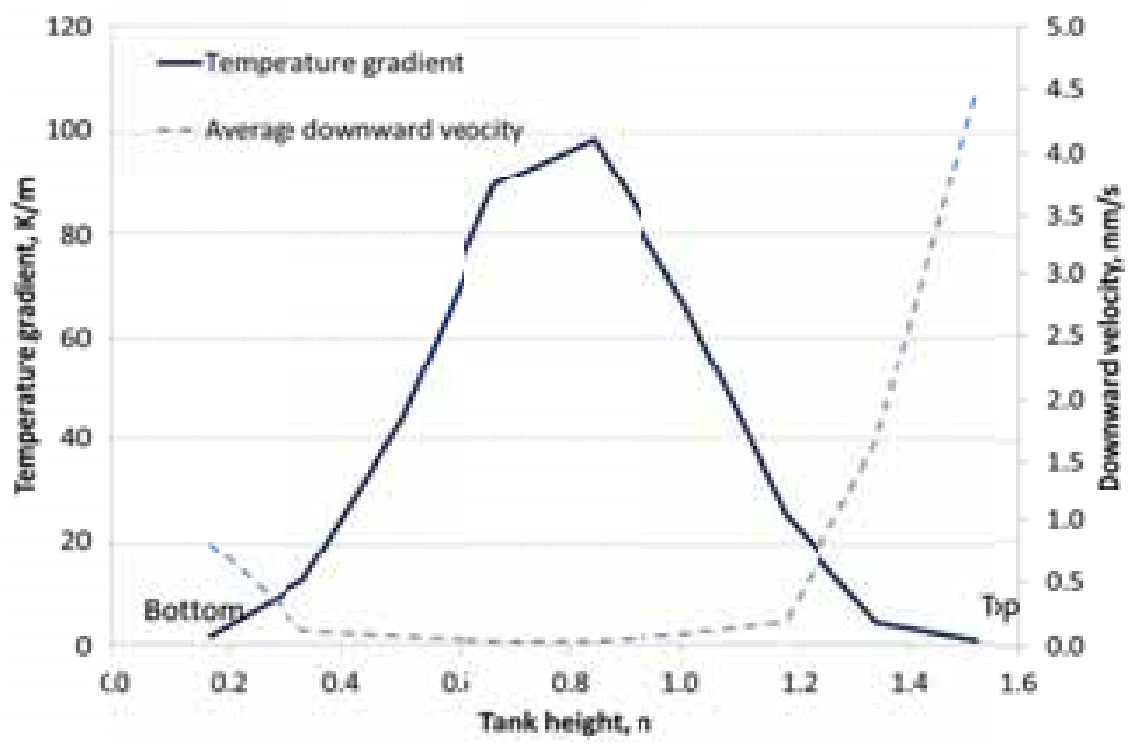

Fig. 8 Dependence of downward velocity on temperature gradient in the tank after 5 hours of standby for a stratified tank.

\section{The heat loss removal factor}

\subsection{Equation of the heat loss removal factor}

In order to quantify the effect of the buoyancy driven flow on exchange of heat loss between tank layers by natural convection, a heat loss removal factor is introduced. Based on the results of previous CFD investigations, a simple equation is obtained by regression that calculates the heat loss removal factor for a given temperature gradient in the tank (Fan 2012b). The equation takes into account the influences of tank volume, tank height to diameter ratio, tank insulation, thickness and property of the tank wall and initial conditions of the tank, see equation (8).

$G r(I) \leq 0.25: a(I)=0.65-G r(I)$

$$
G r(I)>0.25: a(I)=\frac{1}{2.32+1.39 D^{2} H+0.116 H / D} \ln \left(\frac{Q_{\text {loss }}(I+1)}{8.12 H+2.23 D+4.71 / H / D}\right) \operatorname{Gr}(I)^{\frac{T_{\text {layer }(I+1)-T_{a}}^{85.8+39.5 D^{2} H+18.3 H / D}-1}{1}}
$$

(eq. 8)

where $\quad a(I)$ is the heat loss removal factor of the $i$ th tank layer;

$H$ is the tank height in $\mathrm{m}$;

$D$ is the tank diameter in $\mathrm{m}$;

$\mathrm{Q}_{\text {loss }}(\mathrm{I}+1)$ is the heat loss from the side of the tank layer $I+1$ in $\mathrm{W} / \mathrm{m}^{2}$.

$T_{\text {layer }}(\mathrm{I}+1)$ is the average water temperature in the tank layer $\mathrm{I}+1,{ }^{\circ} \mathrm{C}$;

$T_{\mathrm{a}}$ is the ambient air temperature, ${ }^{\circ} \mathrm{C}$;

$\operatorname{Gr}(I)$ is temperature gradient of the $i$ th tank layer in $\mathrm{K} / \mathrm{m}$.

Fig. 9 shows the heat loss removal factor as a function of temperature gradient. In the calculation a tank with a volume of 1501 and a height to diameter ratio of 5 is used. Water temperature in the tank and ambient air temperature is assumed to be $80^{\circ} \mathrm{C}$ and $20^{\circ} \mathrm{C}$ respectively. It is clearly shown that when there is almost no temperature gradient $(<5 \mathrm{~K} / \mathrm{m})$, the heat loss removal factor lies in the range from 0.1 to 0.7 , meaning that $10-70 \%$ of the heat loss accumulated in the layer will be transported downwards. In the region where there is a temperature gradient larger than $5 \mathrm{~K} / \mathrm{m}$, the heat loss removal factor is smaller than 0.1 , which means that 
only an insignificant part of the heat loss is transported downward.

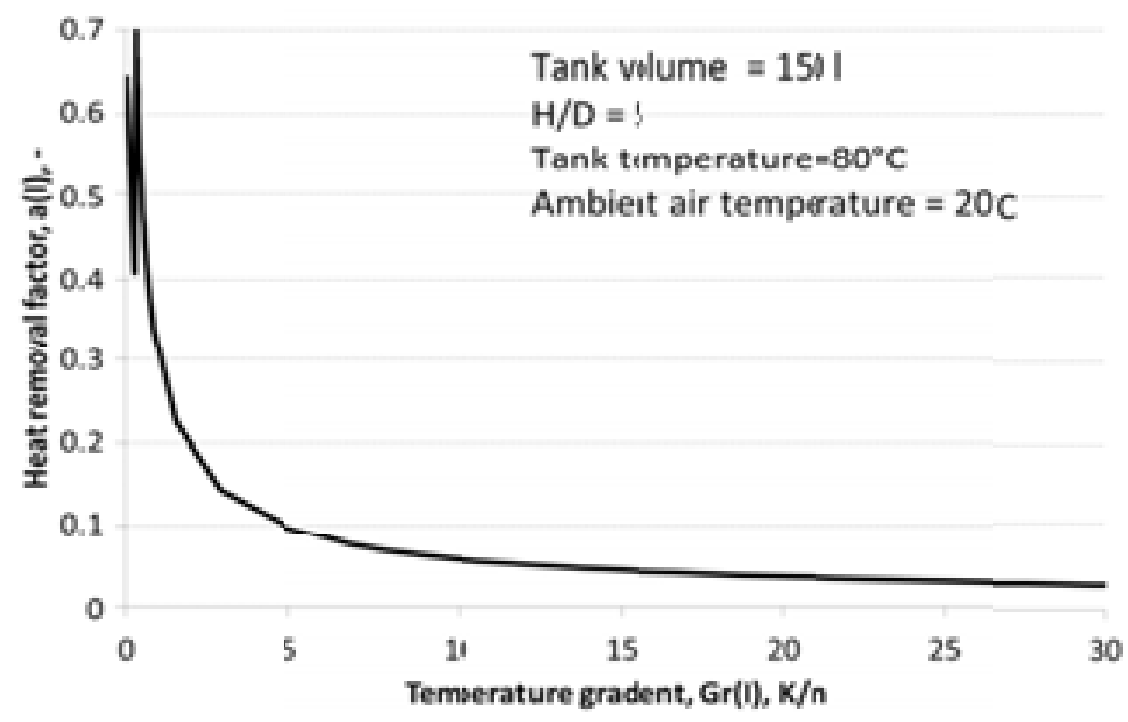

Fig. 9 Heat loss removal factor as a function of temperature gradient in the tank.

\subsection{Comparison between the measured and the simulated water temperatures}

The equation (eq. 8) is implemented in the tank simulation program SpiralSol. Water temperatures calculated by the program is compared to the measured temperatures. Fig. 10 shows a comparison between the measured water temperatures and the simulated water temperatures by the programs with and without using the heat removal factor. The initial condition of the tank is a fully charged tank with a uniform water temperature of $80^{\circ} \mathrm{C}$. The measured water temperatures are shown in curves whille the simulated water temperatures are shown by dots and crosses. After one hour of standby cooling, the water temperature at the bottom of the tank is decreased to $75^{\circ} \mathrm{C}$ while there is a temperature decrease of $0.5 \mathrm{~K}$ in the rest of the tank. After 24 hours standby cooling of the tank, the water temperature at the top of the tank was measured to be $66.4{ }^{\circ} \mathrm{C}$. Water at the bottom of the tank was cooled down to $54.6{ }^{\circ} \mathrm{C}$. The program without the heat removal factor predicts water temperatures of $65.7{ }^{\circ} \mathrm{C}$ and $55.7{ }^{\circ} \mathrm{C}$ at the top and at the bottom of the tank respectively. The disagreement between the measured and the simulated temperatures is $-0.7 \mathrm{~K}$ at the top of the tank and $0.9 \mathrm{~K}$ at the bottom of the tank. With the heat loss removal factor considered in the program, the prediction accuracy of the program is improved slightly. The error of prediction is decreased to $-0.4 \mathrm{~K}$ at the top of the tank and to $0.6 \mathrm{~K}$ at the bottom of the tank. The existing disagreement could be explained by the numerical method of the program. As the tank is divided into 16 layers in the simulation, there is a uniform temperature in each layer. This is not true in reality. The error could be decreased by increasing the number of layers in the calculation but it will significantly increase simulation time. The error could also be due to measurement uncertainty of the heat loss coefficients which are used as inputs in the program.

Fig. 11 shows comparison between simulated water temperatures with and without using the heat loss removal factor. It is shown that there is a similar improvement after 12 hour, 24 hour, 36 hour and 48 hour of natural cooling by using the heat loss removal factor.

A comparison between the measured and the simulated water temperatures is presented in Fig. 12 for an initially stratified tank. There is a good agreement between the simulations and the measurements. Consideration of the heat loss removal factor in the program makes only insignificantly improvement. This could be explained by the fact that the heat loss removal factor will be small for a tank with a large temperature gradient, therefore for a majority part of the tank the difference with and without considering the heat loss removal factor is marginal. 


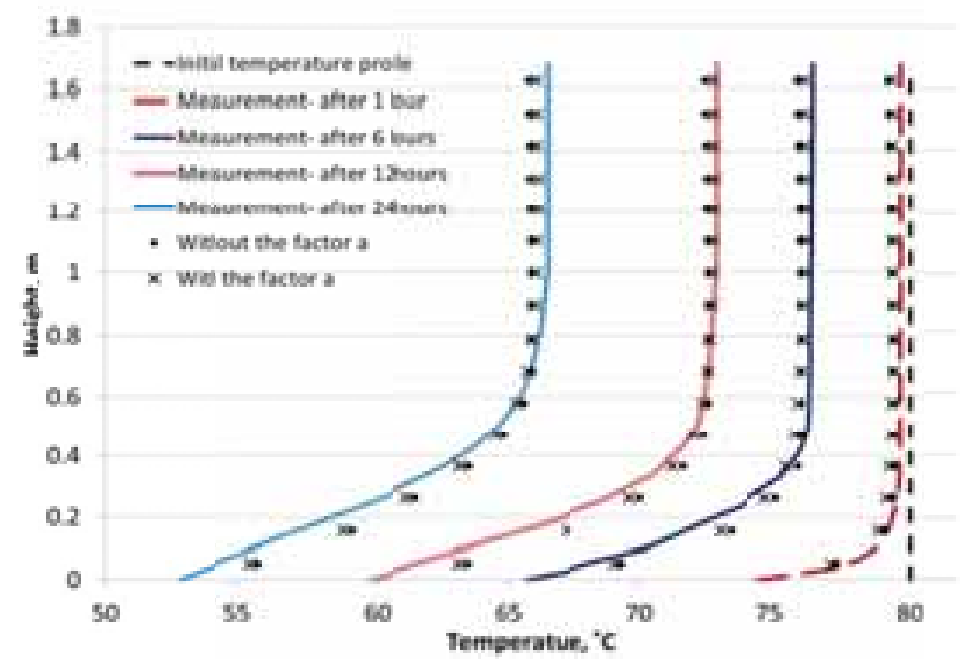

Figure 10. Comparisons between measured and simulated temperatures starting with a fully charged tank.

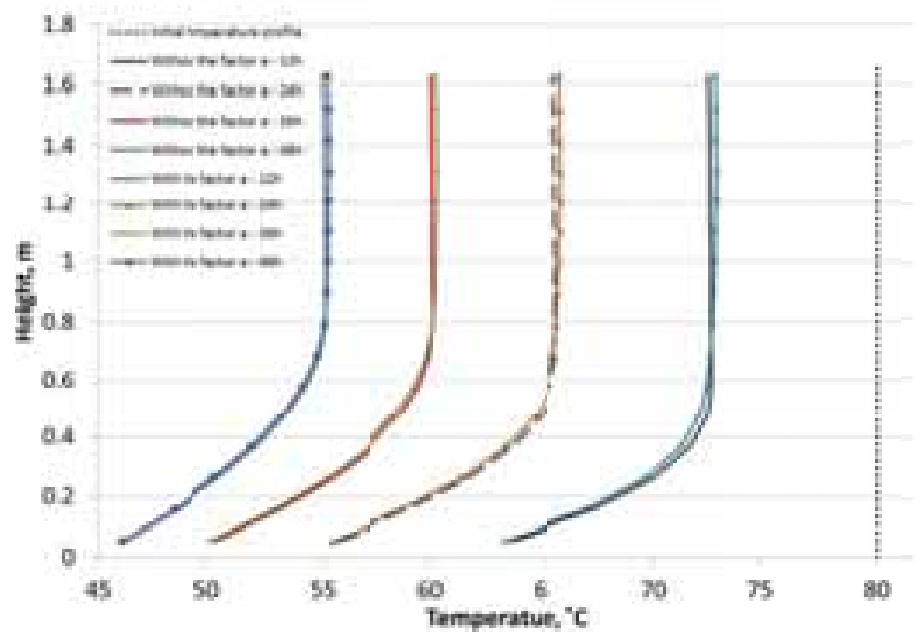

Figure 11. Comparisons between simulated temperatures starting with a fully charged tank.

It can be concluded that for a fully charged tank the prediction accuracy of the program is improved by taking into consideration the heat loss removal factor, while the improvement is marginal for an already stratified tank. Generally there is a good agreement between the simulated and the measured water temperatures, which documents credibility of the program.

The program is then used to calculate thermal performance of a solar heating system with a solar collector of $2 \mathrm{~m}^{2}$, a tank volume of 1501 and a daily tapping of 100 liters. The results show that there is a marginal difference between thermal performance calculated by the program with and without using the heat loss removal factor. This could be explained by the fact that the tank in most of the time is stratified due to 3 times of hot water tapping per day. In a stratified tank the removal of heat loss between layers is minimized due to the presence of temperature gradient in the tank. 


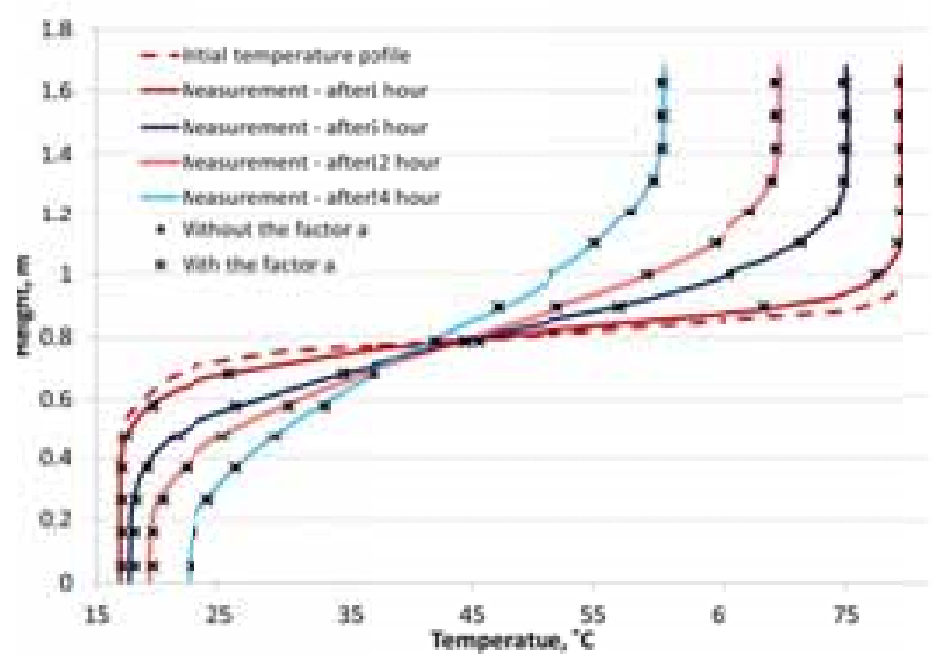

Figure 11. Comparisons between measured and simulated temperatures starting with a stratified tank.

\section{Conclusions}

The downward flow along the tank side wall caused by natural cooling of the tank is investigated by means of validated CFD models. The results show that the downward flow moves water with colder temperature down to a lower level of the tank, thus helping to establish thermal stratification in the tank. The magnitude of the downward flow is significantly influenced by the temperature gradient in the tank. The higher the temperature gradient in the tank, the lower the downward fluid velocity is. For a fully charged tank there is a strong downward flow in most of the tank where the temperature gradient is smaller than $5 \mathrm{~K} / \mathrm{m}$. For a stratified tank the downward flow is only apparent in the upper part of the tank where there is a high water temperature and a low temperature gradient. In the rest of the tank there is limited flow along the tank side wall.

A heat loss removal factor is introduced in the tank simulation program Spiralsol to quantify the effect of the buoyancy driven flow on exchange of heat loss between tank layers by natural convection. A generalized equation of the heat loss removal factor is implemented in the program. The simulated water temperatures in the tank are compared to the measured ones. The results show that for a fully charged tank the prediction accuracy of the program is improved by taking into consideration the heat loss removal factor, while the improvement is marginal for an already stratified tank. Generally there is a good agreement between the simulated and the measured water temperatures, which documents credibility of the program.

The program is then used to calculate thermal performance of a solar heating system with a solar collector of $2 \mathrm{~m}^{2}$, a tank volume of 1501 and a daily tapping of 100 liters. The results show that there is a marginal difference between thermal performance calculated by the program with and without using the heat loss removal factor. This could be explained by the fact that the tank in most of the time is stratified due to 3 times of tapping per day. In a stratified tank the removal of heat loss between layers is minimized due to the presence of temperature gradient in the tank.

\section{Acknowledgements}

This research was supported by the Special fund for the development of small and medium enterprises (EU China Cooperation Program) SQ2013Z0G100002.

\section{References}

Andersen E, Furbo S, Theoretical comparison of solar water/space heating combi systems and stratification design options. Journal of Solar Energy Engineering 2007; 129: 438-448. 
Fan J, Furbo S. Buoyancy driven flow in a hot water tank due to standby heat loss. Solar Energy 2012; 86:3438-3449.

Fan J, Furbo S. Thermal stratification in a hot water tank established by heat loss from the tank. Solar Energy 2012; 86:3460-3469.

Furbo S. Varmelagring til solvarmeanlæge, PhD report, No. 162, Thermal Insulation Laboratory, Technical University of Denmark, 1984.

Furbo S, Mikkelsen S. Is low flow operation an advantage for solar heating systems? Proceedings of the ISES Solar World Congress Hamburg, Germany, Bloss, W. H. and Pfisterer, F., Pergamon Press, Oxford, 1987; 962-966.

Furbo S, Knudsen S. Improved design of mantle tanks for small low flow SDHW systems. International Journal of Energy Research 2006; 30: 955-965.

Geczy-Vig P, Farkas I. Neural network modelling of thermal stratification in a solar DHW storage. Solar Energy 2010; 84: 801-806.

Haller MY, Yazdanshenas E, Andersen E. A method to determine stratification efficiency of thermal energy storage processes independently from storage heat losses. Solar Energy 2010; 84: 997-1007.

Haller M, Cruickshank C, Streicher W, Methods to determine stratification efficiency of thermal energy storage processes-Review and theoretical comparison. Solar Energy 2009; 83: 1847-1860.

Hollands K, Lightstone M. A review of low-flow stratified-tank solar water heating system. Solar Energy 1989;43: 97-105.

van Koppen C, Thomas J, Veltkamp W. The actual benefits of thermally stratified storage in a small and medium size solar systems. Proceedings of the ISES Solar World Congress, 1979, Atlanta, USA, 1979; 579580

Zachar A, Aszodi A. Numerical analysis of flow distributors to improve temperature stratification in storage tanks. Numerical Heat Transfer Part A-applications 2007; 51: 919-940. 